\section{КЛИМАТИЧЕСКИЕ ИЗМЕНЕНИЯ НА ТЕРРИТОРИИ САРАТОВСКОЙ ОБЛАСТИ И ИХ ВЛИЯНИЕ НА УРОЖАЙНОСТЬ СЕЛЬСКОХОЗЯЙСТВЕННЫХ КУЛЬТУР}

\author{
Г.Ф. Иванова, Ю.А. Скляров, Н.Г. Левицкая
}

Саратовский государственный университет, кафедра метеорологии и климатологии

E-mail: vigalo@@mail.ru

В статье анализируется многолетняя изменчивость ряда метеорологических параметров в Саратовской области. За период наблюдений 1930-2004 гг. по шести станциям Саратовской области получены линейные тренды средних, максимальных и минимальных температур воздуха, сумм осадков за различные месяцы и сезоны. Результаты свидетельствуют об уменьшении континентальности климата в регионе.

Climatic Changes in Territory of the Saratov Region and Their Influence on Productivity of Agricultural Crops

\section{G.F. Ivanova, Ju.A. Sklyarov, N.G. Levitskaja}

Long-term variability of some meteorological parameters in the Saratov region is analyzed in this paper. For the period of observation from 1930 to 2004 at six stations in the Saratov region, linear trends of average, maximal and minimal air temperatures, the sum of atmospheric precipitations for various months and seasons have been gained. These results suggest reduction of continentality of a climate in the region.

\section{Введение}

В последние несколько десятилетий произошли заметные изменения температуры воздуха во многих регионах мира. Согласно данным Международной группы экспертов по изменению климата (МГЭИК) [1], средняя годовая глобально осредненная температура воздуха в XX столетии увеличилась на $0,6^{\circ} \mathrm{C}$. Усилившееся в конце $\mathrm{XX}$ в. глобальное потепление привело к крупномасштабным изменениям природной среды. Наблюдается сокращение многих горных ледников, снежного покрова. Отмечается сокращение площади и уменьшение толщины льдов Северного Ледовитого океана. Многочисленные метеорологические аномалии последнего десятилетия прошедшего XX и начала XXI столетий свидетельствуют о происходящем изменении климата.

Существуют разные мнения о причинах современного потепления [2, 3]. Большинство ученых поддерживает точку зрения о том,

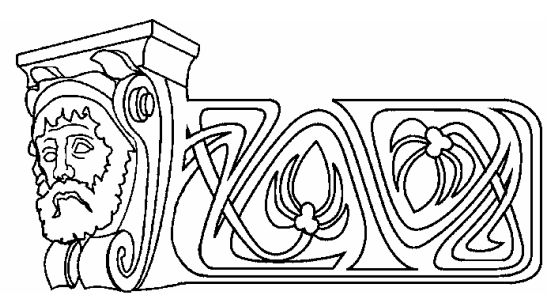

что основной причиной современного потепления является антропогенный фактор, вызванный парниковым эффектом за счет роста углекислого газа, поступающего в атмосферу в результате сжигания ископаемого топлива, и других примесей. В качестве альтернативных гипотез рассматриваются и естественные природные факторы, такие как изменение параметров планетарной орбиты, цикличность в интенсивности приходящего солнечного излучения, увеличение частоты извержений вулканов, ухудшающих прозрачность атмосферы, крупномасштабные осцилляции барического поля.

Результаты многочисленных исследований изменений климата показывают, что для различных широт северного полушария, как для Евразийского, так и для Американского континентов, тренды среднегодовых и среднемесячных температур неоднозначны [1, 4-6].

В настоящее время одной их важнейших задач по проблеме изменения климата является изучение и учет количественных характеристик климатических параметров в определенных физико-географических условиях с целью выявления прямых и обратных связей для экосистем, которые проявляются как в виде негативных, так и позитивных эффектов.

Целью настоящих исследований являлось всестороннее изучение изменчивости климата в Саратовской области на основе многочисленных метеорологических параметров и показателей. Исследования проводились с помощью рассчитанных линейных трендов, достоверность которых оценивалась по методу Стьюдента на 5\%-ном уровне значимости ${ }^{7}$. 


\section{Анализ долговременных трендов}

\section{основных термических характеристик}

Для оценки изменчивости термических характеристик территории были рассчитаны долговременные линейные тренды среднегодовой, среднемесячной, максимальной и минимальной температуры воздуха, а также сумм температур воздуха выше $+10^{\circ} \mathrm{C}$ и сумм отрицательных температур за 1930-2004 гг.

С целью объективной оценки и охвата территории Саратовской области в работе были использованы данные шести метеорологических станций, которые равномерно распределены по указанной территории и представляют основные природные зоны правобережья (станции Балашов, Саратов, Карабулак) и левобережья реки Волги (станции Ершов, Новоузенск, Пугачев).

Проведенные ранее исследования на территории Нижнего Поволжья показывают тенденцию изменения климата по осредненным за месяц и год метеорологическим параметрам [8-12]. В настоящей работе особое внимание было уделено экстремальным метеовеличинам - месячным максимумам и минимумам температуры воздуха. Такой подход к выбору исходных данных определен тем обстоятельством, что именно экстремаль- ные погодные условия способны нанести ощутимый урон различным отраслям народного хозяйства и привести к стихийным бедствиям. В частности, в сельском хозяйстве растения подвержены влиянию ежечасных и ежедневных изменений погоды. А многие растения особо чувствительны к стрессовым ситуациям, когда происходят резкие колебания суточной амплитуды температуры воздуха, интенсивности осадков, длительности сухих и влажных периодов [13].

По данным большинства станций Саратовской области, многолетние тренды среднемесячной температуры воздуха свидетельствуют об их общей закономерности в годовом ходе (табл.1). В зимние месяцы и весной (в марте-апреле) наблюдается существенное повышение температуры воздуха с наибольшими величинами трендов в январе и феврале до $0,5 \ldots 0,9^{\circ} \mathrm{C}$ за 10 лет. В конце весны и в начале лета (в мае-июне) темпы роста температур снижаются до $0,1 \ldots 0,2^{\circ} \mathrm{C}$ за 10 лет, а по данным отдельных станций, становятся незначимыми $\left(0,06 \ldots 0,09^{\circ} \mathrm{C}\right.$ за 10 лет). В июле преобладают, а августе и сентябре повсеместно наблюдаются отрицательные тренды до $0,2^{\circ} \mathrm{C}$ за 10 лет. Причем, если в июле лишь

Т а б л и ц а 1

Линейные тренды среднемесячной температуры воздуха ( $T \mathrm{cp})$, месячных максимумов (Tмакс) и месячных минимумов (Тмин) за 1930-2003 гг. по станциям Саратовской области, ${ }^{\circ} \mathrm{C} / 10$ лет

\begin{tabular}{|c|c|c|c|c|c|c|c|c|c|c|c|c|c|}
\hline Станции & Параметры & I & II & III & IV & $\mathrm{V}$ & VI & VII & VIII & IX & $X$ & XI & XII \\
\hline \multirow{3}{*}{ Карабулак } & $T \mathrm{cp}$ & 0,68 & 0,52 & 0,42 & 0,30 & $\underline{0,11}$ & $\underline{0,10}$ & $-0,02$ & $-0,14$ & $-0,12$ & $\underline{0,11}$ & $-0,06$ & 0,27 \\
\hline & Тмакс & 0,16 & 0,46 & 0,31 & $\underline{0,05}$ & $\underline{0,06}$ & $\underline{-0,08}$ & $-0,17$ & $-0,35$ & $-0,19$ & $\underline{0,06}$ & $-0,29$ & 0,18 \\
\hline & Тмин & 0,65 & 0,27 & 0,7 & 0,26 & $\underline{0,01}$ & 0,25 & $\underline{0,06}$ & $-0,23$ & $\underline{-0,02}$ & 0,23 & $\underline{-0,12}$ & $\underline{0,13}$ \\
\hline \multirow{3}{*}{ Саратов } & $T \mathrm{cp}$ & 0,87 & 0,67 & 0,46 & 0,32 & $\underline{0,10}$ & 0,14 & $\underline{0,02}$ & $-0,16$ & $-0,15$ & 0,13 & $\underline{0,09}$ & 0,43 \\
\hline & Тмакс & 0,17 & 0,31 & 0,20 & $\underline{0,03}$ & $\underline{-0,04}$ & $\underline{-0,09}$ & $-0,32$ & $-0,48$ & $-0,33$ & 0,05 & $-\underline{-0,08}$ & 0,22 \\
\hline & Тмин & 1,00 & 0,46 & 0,90 & 0,45 & 0,22 & 0,38 & 0,15 & $-0,10$ & 0,15 & 0,32 & 0,30 & 0,45 \\
\hline \multirow{3}{*}{ Ершов } & $T \mathrm{cp}$ & 0,85 & 0,57 & 0,47 & 0,32 & $\underline{0,09}$ & $\underline{0,10}$ & $\underline{-0,03}$ & $-0,22$ & $-0,12$ & $\underline{0,10}$ & $\underline{0,04}$ & 0,24 \\
\hline & Тмакс & 0,19 & 0,30 & 0,40 & $\underline{0,09}$ & $\underline{0,04}$ & $\underline{0,07}$ & $\underline{-0,10}$ & $-0,20$ & $\underline{-0,08}$ & $\underline{0,10}$ & 0,30 & 0,20 \\
\hline & Tмин & 0,77 & 0,51 & 0,84 & 0,39 & $\underline{0,10}$ & 0,35 & $-0,22$ & $-0,13$ & $\underline{0,02}$ & 0,29 & $\underline{0,20}$ & 0,24 \\
\hline \multirow{3}{*}{ Новоузенск } & $T \mathrm{cp}$ & 0,94 & 0,64 & 0,57 & 0,38 & 0,17 & 0,21 & $\underline{0,02}$ & $-0,15$ & $-0,17$ & 0,15 & $\underline{0,11}$ & 0,46 \\
\hline & Тмакс & 0,15 & 0,47 & 0,64 & $-\underline{0,06}$ & $\underline{0,08}$ & $\underline{0,09}$ & $-0,16$ & $-0,34$ & $-0,27$ & $\underline{0,10}$ & $-0,56$ & 0,22 \\
\hline & Тмин & 0,98 & 0,93 & 1,38 & 0,47 & 0,34 & 0,51 & 0,31 & $\underline{0,07}$ & 0,22 & 0,44 & 0,48 & 0,72 \\
\hline \multirow{3}{*}{ Балашов } & $T \mathrm{cp}$ & 0,68 & 0,55 & 0,45 & 0,40 & $\underline{0,06}$ & $\underline{0,09}$ & $\underline{-0,04}$ & $-0,17$ & $-0,10$ & $\underline{0,09}$ & $-\underline{-0,03}$ & 0,30 \\
\hline & Тмакс & 0,15 & 0,41 & 0,47 & $\underline{0,14}$ & $\underline{-0,03}$ & $\underline{-0,03}$ & $-0,34$ & $-0,34$ & $-0,15$ & $\underline{0,11}$ & $-0,20$ & 0,30 \\
\hline & Тмин & 0,77 & 0,53 & 1,02 & 0,54 & $\underline{0,02}$ & 0,48 & 0,17 & $\underline{-0,13}$ & 0,14 & $\underline{0,13}$ & $\underline{-0,07}$ & $\underline{0,08}$ \\
\hline \multirow{3}{*}{ Пугачев } & $T \mathrm{cp}$ & 0,90 & $\underline{0,07}$ & 0,51 & 0,36 & $\underline{0,15}$ & 0,19 & $\underline{-0,02}$ & $-0,20$ & $\underline{-0,07}$ & 0,19 & 0,12 & 0,45 \\
\hline & Тмакс & 0,34 & 0,47 & 0,41 & $\underline{0,06}$ & $\underline{0,10}$ & $\underline{0,05}$ & $-0,24$ & $-0,30$ & $-0,15$ & $\underline{-0,11}$ & $-0,27$ & 0,20 \\
\hline & Тмин & 0,81 & 0,56 & 0,91 & 0,60 & $\underline{0,13}$ & 0,39 & 0,13 & $\underline{-0,03}$ & $-0,13$ & 0,28 & 0,28 & $\underline{0,11}$ \\
\hline
\end{tabular}

Примечание. Подчеркнуты статистически незначимые линейные тренды (5\%-ный уровень по критерию Стьюдента). 
местами, то в августе и сентябре повсеместно отрицательные тренды температуры статистически значимые, что свидетельствует об устойчивой закономерности их снижения. В октябре и ноябре только в Пугачеве отмечались значимые положительные тренды, а по остальным станциям преобладают положительные незначимые тренды.

Для месячных максимумов температуры в многолетнем ходе характерен устойчивый рост зимой и в начале весны (с декабря по март) со скоростью $0,2 \ldots 0,5^{\circ} \mathrm{C}$ за 10 лет и их снижение в летние и в отдельные осенние месяцы (в сентябре и ноябре) на $0,1 \ldots 0,3^{\circ} \mathrm{C}$ за 10 лет. В апреле, в мае и в июне в многолетнем ходе месячных максимумов температуры не наблюдается однотипных тенденций по станциям, и тренды повсеместно незначимые. В октябре, за исключением Пугачева, по станциям положительные незначимые тренды.

Месячные минимумы растут на всех метеостанциях во все месяцы года за исключением августа. С наибольшими темпами минимумы температуры воздуха растут зимой и в марте, со скоростью $0,27 \ldots 1,0^{\circ} \mathrm{C}$ за 10 лет. $\mathrm{B}$ апреле и в июне темпы роста минимумов снижаются и составляют $0,3 \ldots 0,6^{\circ} \mathrm{C}$ за 10 лет. В мае и июле минимумы также растут, но еще менее интенсивно, $0,01 \ldots 0,34^{\circ} \mathrm{C}$ за 10 лет. В августе наблюдается снижение уровня температурных минимумов на $0,19 \ldots 0,03^{\circ} \mathrm{C}$ за 10 лет, однако по большинству станций (Пугачев, Балашов и Новоузенск) это снижение незначимое.

Анализ полученных результатов показал, что рост средних месячных температур в зимние, весенние месяцы и в начале лета (в июне) обусловлен существенным повышением месячных минимумов и максимумов. Причем из-за существенных ростов минимумов их преобладающая роль в повышении среднемесячных температур очевидна.

Потепление зим, естественно, ведет к изменению других параметров, связанных, например, с датами перехода температуры через определенные значения: $0^{\circ}, 5^{\circ}, 10^{\circ} \mathrm{C}$. За исследуемый 65-летний период весной переход через $0^{\circ}$ и $5^{\circ} \mathrm{C}$ сдвинулся и происходит на 5-6 дней раньше, а дата перехода через $10^{\circ} \mathrm{C}$ весной практически не поменялась.
Осенью переход через $0^{\circ}$ и $5^{\circ} \mathrm{C}$ в сторону понижения происходит на 5-7 дней позже по сравнению с 1930 г., а через $10^{\circ} \mathrm{C}-$ на 2 дня позже. Таким образом, продолжительность теплого периода увеличивается, а холодного, наоборот, уменьшается.

Изменение продолжительности сезонов может сказаться на суммарных величинах положительных и отрицательных температур, что, безусловно, весьма важно для произрастания как озимых, так и яровых сельскохозяйственных культур. Тренды сумм отрицательных температур за период 19712004 гг. свидетельствуют об их уменьшении со скоростью $68 \ldots 122^{\circ} \mathrm{C}$ за 10 лет по левобережью и $47 \ldots 78^{\circ} \mathrm{C}$ за 10 лет по правобережью. Одновременно наблюдается увеличение сумм положительных температур выше $10^{\circ} \mathrm{C}$. Темпы роста сумм положительных температур составляют $17 \ldots 33^{\circ} \mathrm{C}$ за 10 лет по правобережью и $14 \ldots 49^{\circ} \mathrm{C}$ за 10 лет по левобережью, что значительно меньше темпов снижения сумм отрицательных температур.

\section{Установленные признаки уменьшения континентальности} климата в Саратовской области

Континентальность климата оценивается главным образом величиной годовой амплитуды температуры воздуха. Среднегодовые температуры воздуха увеличились по всем станциям (табл.2): по правобережью на $1,8 \ldots 2,4^{\circ} \mathrm{C}$ за 100 лет, а по левобережью на $2,0 \ldots 3,1^{\circ} \mathrm{C}$ за 100 лет. При этом годовые максимумы температуры уменьшились по правобережью на $2,2 \ldots 3,3^{\circ} \mathrm{C}$ за 100 лет, а по левобережью - на $1,0 \ldots 1,6^{\circ} \mathrm{C}$ за 100 лет. В противоположность максимумам годовые минимумы повсеместно увеличились: по правобережью - на $3,1 \ldots 6,9^{\circ} \mathrm{C}$ за 100 лет, а по левобережью - на $2,0 \ldots 9,6^{\circ} \mathrm{C}$ за 100 лет. Уменьшение годовых максимумов и существенное увеличение годовых минимумов привели к снижению годовых амплитуд температуры воздуха, тренды которых составили: по правобережью 5,3.. 10,2 ${ }^{\circ} \mathrm{C}$ за 100 лет, а по левобережью $6,7 \ldots 11,2^{\circ} \mathrm{C}$ за 100 лет.

Для оценки изменчивости континентальности климата в Саратовской области по шести станциям были рассчитаны индексы Иванова. По всем станциям они имеют отрицательный знак (табл. 2). Причем по право- 
Линейные тренды среднегодовой температуры воздуха $(T$ ср.г), годового максимума (ТГ.макс), годового минимума (ТГ.мин), годовой амплитуды (ТГ.амп), ${ }^{\circ} \mathrm{C} / 10$ лет, индекса континентальности Иванова $\left(K_{И}\right), \% / 10$ лет за 1930-2003 гг. по станциям Саратовской области

\begin{tabular}{|l|c|c|c|c|c|}
\hline \multicolumn{1}{|c|}{ Станции } & Тср.г & $T_{\text {г.макс }}$ & $T_{\text {г.мин }}$ & $T_{\text {г.амп }}$ & $K_{\text {И }}$ \\
\hline Балашов & 0,22 & $-0,22$ & 0,51 & $-0,73$ & $-4,24$ \\
\hline Саратов & 0,24 & $-0,33$ & 0,69 & $-1,02$ & $-5,48$ \\
\hline Карабулак & 0,18 & $-0,22$ & 0,31 & $-0,53$ & $-4,27$ \\
\hline Ершов & 0,20 & $-0,10$ & 0,57 & $-0,67$ & $-5,09$ \\
\hline Новоузенск & 0,31 & $-0,16$ & 0,96 & $-1,12$ & $-5,57$ \\
\hline Пугачев & 0,27 & $-0,14$ & $\underline{0,20}$ & $-0,82$ & $-5,42$ \\
\hline
\end{tabular}

Примечание. См. табл. 1.

бережью снижение индекса Иванова составляет $42,4 \ldots 54,8 \%$ за 100 лет, а по левобережью - 42,4...55,7\% за 100 лет. Таким образом, в результате существенного потепления зим и снижения летних температур годовая амплитуда колебания температуры воздуха существенно снизилась, что привело к уменьшению континентальности климата в регионе.

\section{Изменение месячных и сезонных сумм осадков}

В работе исследовались месячные суммы осадков за период 1936-2004 гг. Наибольших величин тренды месячных сумм осадков достигают по всем станциям зимой, с декабря по февраль, от 2 до 4 мм за 10 лет (табл.3). Весной, в марте и апреле, тренды сумм осадков также положительные, но их величины меньше предыдущих, от 0,3 до 1,3 мм за 10 лет. В мае наблюдаются отрицательные тренды сумм осадков, $-1,7 \ldots-3,3$ мм за 10 лет. В начале лета, в июне, отмечается повсеместный рост осадков от 0,8 до 4 мм за 10 лет. В июле на станциях преобладают незначимые тренды обоих знаков, за исключением Балашова, где отмечается рост осадков. В августе наблюдается уменьшение осадков со скоростью $0,4 \ldots 2,8$ мм за 10 лет. Но эти изменения местами незначимые. Осенью, в сентябре, отмечается увеличение осадков $(3,3 \ldots 4,7$ мм за 10 лет), в октябре - незначительное уменьшение осадков. В ноябре преобладает рост осадков, $0,8 \ldots 2,3$ мм за 10 лет.

Исследование изменчивости годовых сумм осадков путем построения линейных трендов свидетельствует о повсеместном увеличении
Линейные тренды месячных сумм осадков за 1936-2004 гг., мм/10 лет

\begin{tabular}{|c|c|c|c|c|}
\hline Месяцы & Саратов & Балашов & Ершов & Новоузенск \\
\hline I & 2.34 & 3.01 & 1.76 & 1.73 \\
\hline II & 1,74 & 1,46 & 1,20 & 1,20 \\
\hline III & $\underline{0,31}$ & $\underline{0,40}$ & $\underline{0,34}$ & $\underline{0,50}$ \\
\hline IV & $\underline{0,45}$ & $\underline{-0,25}$ & $\underline{0,04}$ & 1,32 \\
\hline V & $-3,34$ & $-1,72$ & $-2,60$ & $-2,70$ \\
\hline VI & $\underline{0,83}$ & 4,06 & 2,70 & 1,76 \\
\hline VII & $\underline{-0,94}$ & 1,87 & $\underline{-0,31}$ & $\underline{0,17}$ \\
\hline VIII & $\underline{-1,38}$ & $-2,75$ & $\underline{-0,98}$ & $\underline{-0,45}$ \\
\hline IX & 4,71 & 3,87 & 4,20 & 3,32 \\
\hline X & $\underline{-1,58}$ & $\underline{-0,74}$ & $\underline{-0,36}$ & $\underline{-1,07}$ \\
\hline XI & $\underline{1,43}$ & 2,34 & $\underline{0,76}$ & $\underline{-0,37}$ \\
\hline XII & 2,81 & 3,50 & 2,34 & 1,87 \\
\hline
\end{tabular}

Примечание. См. табл. 1.

их количества (от 7 до 15 мм за 10 лет) (табл. 4). При этом наиболее существенный рост осадков наблюдается в холодный период (5..11 мм за 10 лет). В теплый период увеличение осадков незначительное, от 2 до 5 мм за 10 лет. За основной вегетационный период (май-июль) тренды сумм осадков по станциям отрицательные и незначимые, $0,2 \ldots 3,4$ мм за 10 лет. Лишь только в Балашове тренд остается положительным и равен 4,2 мм за 10 лет. В Саратове тренды сумм осадков за весь теплый период и основной вегетационный период (май-июль) отрицательные и статистически незначимые.

Т а б ли ц а 4 Линейные тренды годовых и сезонных сумм осадков за 1936-2004 гг., мм /10 лет

\begin{tabular}{|l|c|c|c|c|}
\hline \multicolumn{1}{|c|}{ Станции } & За год & $\begin{array}{c}\text { Ноябрь- } \\
\text { март }\end{array}$ & $\begin{array}{c}\text { Апрель- } \\
\text { октябрь }\end{array}$ & $\begin{array}{c}\text { Май- } \\
\text { июль }\end{array}$ \\
\hline Саратов & 7,40 & 8,74 & $\underline{-1,24}$ & $-3,45$ \\
\hline Балашов & 14,85 & 10,86 & 4,35 & 4,22 \\
\hline Ершов & 11,06 & 6,64 & 4,66 & $\underline{-0,21}$ \\
\hline Новоузенск & 7,28 & 5,34 & $\underline{2,35}$ & $\underline{\underline{-0,77}}$ \\
\hline
\end{tabular}

Примечание. См. табл. 1.

Примечательной особенностью в последние годы является увеличение частоты выпадения обильных осадков. В Саратове за период 1985-2004 гг. число случаев с суточ- 
ной суммой осадков, превышающих $80 \%$ месячной нормы, увеличилось в теплый период, по сравнению с 1965-1984 гг., в 1,7 раза, а в сентябре - в 8 раз.

\section{Оценка влияния изменившихся климатических условий на урожайность сельскохозяйственных культур}

Изменения климатических условий оказывают значительное влияние на условия произрастания и продуктивность сельскохозяйственных культур в регионе.

Успешность возделывания озимых культур в немалой степени зависит от климатических условий осенне-зимнего периода. Увеличение продолжительности вегетационного периода и улучшение влагообеспеченности второй половины осенней вегетации озимых необходимо учитывать при определении оптимальных сроков сева озимых. Очевидно, что в складывающихся климатических условиях целесообразно их смещение на более поздние даты.

Выявленные изменения осенней влагозарядки почвы и преобладание экстремально высокого температурного режима зимой следует принимать во внимание при обосновании целесообразности проведения снегозадержаний и других агротехнических мероприятий по дополнительному накоплению влаги в почве в зимний период.

Наблюдаемые тенденции в изменении термического режима холодного периода существенно влияют на условия перезимовки озимых культур. С одной стороны, более мягкие зимы благоприятны для зимующих растений, а с другой - продолжительные глубокие оттепели нередко обусловливают полный сход снежного покрова, способствуют образованию на полях притертой к земле ледяной корки, приводят к утрате морозостойких качеств растений. В условиях роста вариабельности температуры по месяцам все это увеличивает вероятность повреждения озимых при резком понижении температуры. Выигрывать в складывающихся условиях будут более пластичные сорта, способные экономнее расходовать запасы накопленных питательных веществ.

Расчет коэффициентов вариации средней по области урожайности основных зерновых культур за 1961-1980 и 1981-2000 гг. свидетельствует об увеличении вариабельности урожайности всех трех групп культур: озимых, ранних и поздних яровых. При этом наибольший рост коэффициентов вариабельности наблюдается у яровой пшеницы.

Рост температуры воздуха и существенное снижение количества осадков, выпадающих в начальный период развития ранних яровых культур, особенно в фазы кущения и выхода в трубку (май), негативно сказываются на их урожайности.

Наблюдаемое снижение континентальности климата ухудшает условия формирования хорошего качества урожая яровой пшеницы. Расчеты показывают, что за период с 1971 по 2000 г. величина биохимического потенциала климата в Саратове уменьшилась с $13,1 \%$ в начале до $12,6 \%$ в конце периода.

Приведенные в статье данные свидетельствуют о достаточно существенном изменении агроклиматических условий региона. Выявленные тенденции изменения основных климатических параметров необходимо учитывать при подборе видового и сортового состава возделываемых культур, рационального их размещения и корректировке технологий возделывания. Правильная стратегия сельскохозяйственного производства будет способствовать снижению негативных последствий изменения климата и повышению эффективности использования биоклиматического потенциала.

\section{Библиографический список}

1. Анисимов О.А., Белолуц̧кая М.А., Лобанов В.А. Современные изменения климата в области высоких широт Северного полушария // Метеорология и гидрология. 2003. №1. C.18-29.

2. Будыко М.И., Ефимова Н.А., Лугина К.М. Современное потепление // Метеорология и гидрология. 1991. №4. C.84-94.

3. Израэль Ю.А., Назаров И.М. Проблема опасного антропогенного воздействия на климатическую систему Земли // Метеорология и гидрология. 2004. №11. С.5-16.

4. Переведенцев Ю.П., Верещагин М.А., Шанталинский К.М. $u$ дp. Современные глобальные и региональные изменения окружающей среды и климата. Казань, 1999. 96 с.

5. Ранькова Э.Я., Груза Г.В. Индикаторы изменений климата // Метеорология и гидрология. 1998. №1. С.5-17.

6. Kukla G., Karl T.R. Nighttime warming and the greenhouse enffect // Environ. Sci. Technol. 1993. V.27, №8. P.1468-1474.

7. Гмурман B.E. Теория вероятности и математическая статистика. М., 2003. 479 с.

8. Дмитриев А.А., Скляров Ю.А., Шабельников А.В. и др. Изменчивость осадков, температуры и солнечная активность / Под ред. Ю.А.Склярова. Саратов, 1990. 112 с. 
9. Левиикая Н.Г., Шаталова О.В. Современные тенденции изменения климата и их влияние на продуктивность сельскохозяйственных культур в Нижнем Поволжье // Проблемы и пути преодоления засухи в Поволжье. Саратов, 2000. Ч.2. С.33-47.

10. Рыхлов А.Б., Левицкая Н.Г. Изменения климата и их агроклиматические последствия в Нижнем Поволжье // Современные глобальные и региональные изменения геосистем: Материалы Всерос. науч. конф., посвящ. 200-летию Казанского ун-та. Казань, 19-21 окт. 2004 г. Казань, 2004. C.370-371.
11. Скляров Ю.А., Иванова Г.Ф. Проблема глобального и регионального изменения климата // Изв. Сарат. ун-та. Новая сер. 2002. Т.2, вып.2. С.44-48.

12. Скляров Ю.А., Иванова Г.Ф. Некоторые аспекты изменения климата и прогнозные оценки для города Саратова / Сарат. гос. ун-т. Саратов, 2003. 20 с. Деп. в ВИНИТИ 30.09.03 г. № 1749-В 2003.

13. Суркова Г.В., Пона К. Колебания изменчивости температуры воздуха и атмосферных осадков как агрометеорологический фактор // Метеорология и гидрология. 2000. №6. C.85-99. 